\title{
Epigenética e doenças humanas
}

\section{Epigenetics and human diseases}

\author{
Jaqueline Carvalho de Oliveira ${ }^{1}$
}

\section{Resumo}

O termo epigenética é definido pela alteração herdável na expressão gênica, sem que haja mudança na sequência primária de DNA, sendo a metilação do DNA e a modificação de histonas, importantes mecanismos envolvidos. A metilação do DNA influencia a organização da cromatina, e leva à repressão de genes e elementos transponíveis. As modificações pós-traducionais que podem ocorrem em proteínas histonas são muitas e podem ocorrer em diferentes aminoácidos e diferentes posições, e resultam em uma multiplicidade de combinações em um verdadeiro "código de histona", e elas são interpretadas por diferentes fatores celulares. As marcas epigenéticas atuam simultaneamente para regular a transcrição gênica em um processo complexo, e pequenas falhas no estabelecimento ou manutenção desses podem desencadear o desenvolvimento de patologias, como a encontrada em síndromes genéticas e no câncer. Devido ao grande número de doenças, muitas pesquisas têm sido realizadas na busca de drogas capazes de reverter esses defeitos epigenéticos. Atualmente, já foram descritos alguns agentes capazes de interferir na ação de enzimas que regulam os processos, porém, existem ainda muitas dúvidas na aplicatividade desses tratamentos, se fazendo necessário maiores estudos dos mecanismos epigenéticos para, no futuro, serem mapeadas vias de interferências específicas e um melhor controle de efeitos.

Palavras-chave: Epigenética. Doenças. Metilação do DNA. Modificação de histona.

\begin{abstract}
The term epigenetics defines heritable changes in gene expression that do not involve DNA sequence changes. DNA methylation and histone modifications are two important related mechanisms. DNA methylation alters chromatin structure and has been shown to have a direct effect on the silencing of genes and transposons. There are many post-traductional modifications on histones and an extra complexity comes from many sites and amino acids that may be modified, what results in multiple matches in a real "histone code" decrypted by different cell factors. The epigenetics mechanisms are complex, and minor failing in the establishment and maintenance causes diseases, as genetics syndromes and cancer. Due to several diseases, an increasing amount of research has been realized to find drugs able to suppress these defects. Nowadays, there have already been described some medicines able to interfere in the action of the enzymes which regulate the epigenetic processes, however, there is still doubt in effectiveness of theses treatment. It is necessary additional research about epigenetics mechanism to, in the future, understand specific pathways and control the effects of these drugs.
\end{abstract}

Keywords: Epigenetics. Diseases. DNA methylation. Histone modifications.

\footnotetext{
1 Biomédica, Universidade Estadual de Londrina (2007), Mestre em Ciências Biológicas, área: Genética (2009), Faculdade de Medicina de Ribeirão Preto - USP, atualmente desenvolve projeto de doutorado junto ao Departamento de Genética, Departamento de Genética, Faculdade de Medicina de Ribeirão Preto, Universidade de São Paulo, USP (FMRP-USP). Rua Roque Nacarato, 741 ap 22, CEP: 14051 000, Ribeirão Preto, SP. E-mail: oliveirajc@usp.br
} 


\section{Epigenética e Doenças Humanas}

O termo epigenética é definido pela alteração herdávelnaexpressãogênica,semquehajamudançana sequência primária de DNA(WOLFFE; GUSCHIN, 2000). Acredita-se que os mecanismos epigenéticos são os parâmetros flexíveis do genoma capazes de serem alterados em face de diversos estímulos. Eles são estáveis à propagação do genoma ativo durante as múltiplas divisões celulares, e a metilação do DNA e a modificação de histonas constituem dois importantes mecanismos regulatórios conhecidos (BOLLATI; BACCARELLI, 2010).

O conjunto das modificações epigenéticas, denominado epigenoma, é característico ao tipo celular e fornecem mecanismos à diversidade e diferenciação, por meio da regulação da acessibilidade da informação genética para a maquinaria celular. Falhas no estabelecimento ou manutenção das marcas epigenéticas podem resultar na ativação ou inibição imprópria de vários genes e alterar a fisiologia celular normal, levando ao desenvolvimento de patologias (EGGER et al., 2004; SHARMA; KELLY; JONES, 2010).

\section{Metilação do DNA}

A metilação do DNA é a modificação epigenética melhor caracterizada e reconhecida como um mecanismo de silenciamento. Consiste na adição de um radical metil $\left(\mathrm{CH}_{3}\right)$ no carbono 5 de Citosina, geralmente seguida por Guanina (dinucleotídeo $\mathrm{CpG}$ ), catalisada por enzimas DNA metiltransferases (DNMTs) (PAULSEN; FERGUNSON-SMITH, 2001).

Em mamíferos foram identificadas três classes principais de DNMTs: DNMT1, DNMT2 e DNMT3. A DNMT1, também denominada metiltransferase de manutenção, está envolvida no processo de metilação que ocorre durante a divisão celular mitótica, copiando o padrão de metilação da fita original (PRADHAN et al., 1999; TAKEBAYASHI et al., 2007). A classe de DNMT3 é subdividida em A e B, e está relacionada à aquisição de metilação de DNA de novo (DNA não-metilado previamente) (OKANO et al., 1999). Já a DNMT2, embora apresente toda estrutura de uma DNA metiltransferase, parece não apresentar essa atividade, pois está relacionada com a ação metiltransferase de RNA transportador e recentemente, em Arabidopsis, com a desacetilação de histona (GOLL et al., 2006; SONG et al., 2010).

As citosinas seguidas de guaninas (sítios CpGs) são assimetricamente distribuídos em regiões com poucos CGs e em regiões ricas em CGs, denominadas "ilhas CpGs". Em termos mais explícitos, considerase que as ilhas são caracterizadas por conterem mais de 500 pares de bases e destas, mais de 55\% sendo CGs (TAKAI; JONES, 2002), sendo essas geralmente localizadas na porção 5' do gene. Estima-se que as ilhas CpGs estejam presentes em cerca de 50 a $70 \%$ de todos os promotores de genes humanos, já as regiões com poucos CGs geralmente são localizadas em porções intergênicas e intrônicas (SAXONOV; BERG; BRUTLAG, 2006; WANG; LEUNG, 2004).

Nas células normais, as regiões com CGs distribuídas pelo genoma geralmente são metiladas, permanecendo as ilhas CpGs hipometiladas, adquirindo metilação para a regulação gênica. Nas fases iniciais do desenvolvimento, é verificado um nível baixo de metilação global, com cerca de 30\% das regiões metiladas, entre elas, regiões envolvidas na regulação do imprinting genômico (expressão diferencial de alelos de acordo com a origem parental e regulado por mecanismos epigenéticos, ou seja, apenas um dos alelos contém a marcação) e na inativação do cromossomo X. Com as múltiplas divisões celulares e durante a diferenciação tecidual, as marcas de metilação vão sendo colocadas, e disso resulta a metilação da grande maioria dos sítios CpGs no organismo formado, e deles permanece apenas uma pequena fração (1-2\%) sem essa marca (SUZUKI et al., 2008; GEIMAN; MUEGGE, 2010).

Com o avançar da idade, há uma nova inversão gradual do perfil de metilação, com uma perda global 
da metilação e também a metilação esporádica de alguns sítios. Essa alteração da metilação é altamente pronunciada durante a carcinogênese (EHRLICH, 2009; GILBERT, 2009; JINTARIDTH; MUTIRANGURA, 2010).

A metilação é a marca epigenética melhor estudada, tendo seu papel evidenciado na regulação da expressão gênica por inúmeros trabalhos. Muitos dos mecanismos envolvidos com o estabelecimento e manutenção da metilação em sítios específicos do DNA ainda são desconhecidos, porém é certa a influência que essa modificação epigenética desempenha na organização da cromatina, levando à repressão de inúmeros genes e elementos transponíveis (MIRANDA; JONES, 2007).

Em 2007, McGarvey e colaboradoes, demonstraram que a metilação do DNA foi capaz de prevenir a reativação de genes silenciados, mesmo quando os marcadores repressivos de histona foram revertidos.

O mecanismo mais simples de como a metilação do DNA pode atuar no controle da expressão gênica é por meio do bloqueio do sítio promotor ao acesso de fatores de transcrição, havendo silenciamento do alelo metilado, ou seja, a metilação do DNA interfere diretamente na sequência de ligação de fatores (PRENDERGAST; LAWE; ZIFF, 1991; MIRANDA; JONES, 2007).

Um exemplo clássico desse mecanismo de regulação ocorre com a proteína CTCF (fator de ligação CCCTC), um fator de transcrição com domínios dedos-de-zinco. A metilação em regiões promotoras alvo dessa proteína previne a ligação e ativação de toda uma cascata de transcrição, levando a inativação do gene específico (MONK et al., 2008). Esse mecanismo, por exemplo, é o que é observado na regulação dos genes c-myc (PRENDERGAST; LAWE; ZIFF, 1991; GOMBERT; KRUMM, 2009).

A metilação do sítio de ligação da proteína CTCF também é importante na regulação que ocorre no centro regulador de imprinting 1 , na região 11 p15 do cromossomo humano. Essa região, também chamada H19DMR, é mapeada $2 \mathrm{~kb}$ upstream ao gene H19, gene maternalmente expresso, que codifica um RNA não-codificante de função ainda desconhecida. Nesse domínio, também está presente o gene IGF2 cujo alelo expresso é o paterno e codifica um fator de crescimento semelhante à insulina (Insulin Like Growth Factor II), sendo um dos principais reguladores do crescimento fetal e pós-natal (DELAVAL; WAGSCHAL; FEIL, 2006).

Estudos em camundongos mostraram que o alelo não metilado materno é ligado a muitas cópias da proteína de "dedos de zinco" denominada CTCF (VERONA; MANN; BARTOLOMEI, 2003). Essa ligação cria um limite de cromatina, que atua como inibidor do gene $I G F 2$ e acentuador da expressão do H19. Como conseqüência, o $I G F 2$ não é expresso a partir do alelo materno. No alelo paterno, há a metilação do DNA e não há a ligação da CTCF, permitindo o acesso do acentuador ao IGF2. Durante as etapas iniciais do desenvolvimento, a metilação do DNA paterno se estende da ICR até o promotor do H19, guiando a repressão do alelo paterno. Em resumo, a manutenção da diferença de metilação do DNA na H19DMR garante que o gene IGF2 seja expresso apenas no alelo paterno e do H19, no materno (VERONA; MANN; BARTOLOMEI, 2003; MOSS; WALLRATH; 2007).

Embora a prevenção de ligação de fatores de transcrição em promotores metilados seja um mecanismo importante, esse mecanismo não foi verificado na maioria dos fatores de transcrição, sugerindo que existam outros processos envolvidos e, possivelmente, muitos ainda não identificados. Um exemplo de mecanismo potencial foi identificado com a descrição de que a metilação pode afetar os sítios de interação da fita de DNA com o nucleossomo, o que pode diminuir a ligação com fatores de transcrição e a RNA polimerase II (DAVEY et al., 2004; LI; CAREY; WORKMAN, 2007).

Outro mecanismo proposto se baseia na possibilidade da metilação do DNA influenciar 
enzimas que afetam modificações de histonas. Por exemplo, a metilação pode interagir com proteínas que apresentam domínios de ligação à metilação e modular a expressão gênica através da interação com histonas deacetilalases (HDACs) (JONES et al., 1998; NAN et al., 1998) ou H3K4 metiltransferases (RUTHENBURG; ALLIS; WYSOCKA, 2007).

\section{Modificações de Histona}

Sabe-se que, em eucariotos, o DNA é compactado em cromatina e essa pode estar organizada em heterocromatina, com baixa atividade transcricional ou em eucromatina, ativa. O nucleossomo é a unidade básica da cromatina, sendo seu cerne composto por duas moléculas de histonas H2A, H2B, H3 e H4 cada e envolvido por 147 pares de nucleotídeo de DNA. Existem inúmeras modificações pós-traducionais envolvendo essas moléculas, sendo importantes mecanismos epigenéticos no controle da expressão gênica (KOUZARIDES, 2007).

Já foram descritos pelo menos oito tipos de alterações em histonas como acetilação, metilação, fosforilação, ubiquitibação, sumoilação, ADPribosilação, deaminação e isomerização de prolina, além de poderem ser situadas em diferentes posições, sendo relatados mais de 60 resíduos possíveis. Isso demonstra a grande complexidade desses mecanismos, que resultam em uma multiplicidade de possíveis combinações, constituindo um verdadeiro "código de histona", que são interpretados por diferentes fatores celulares (EGGER et al., 2004; KOUZARIDES, 2007).

As modificações de histona atuam na regulação da transcrição gênica, pois interferem na condensação da cromatina que é estritamente relacionada a áreas de acesso ou não do DNA à maquinaria transcricional, podendo também recrutar e/ou impossibilitar o acesso a proteínas efetoras nãohistona (SHARMA; KELLY; JONES, 2010).

A maioria das marcas epigenéticas conhecidas não tem seus mecanismos totalmente elucidados, entretanto, o papel da acetilação e metilação de lisina tem sido evidenciado na ativação e repressão gênica.

A acetilação da lisina na porção amino terminal da histona 3 (H3) ou histona 4 (H4), por exemplo, é encontrada em regiões ativas transcricionalmente, já a hipoacetilação é encontrada em regiões de baixa atividade (YAN; BOYD, 2006; BOLLATI; BACARELLI, 2010).

A metilação de lisina pode ser relacionada a áreas ativas ou inativas, dependendo do resíduo a que está relacionada. A metilação de lisina 9 ou 27 na porção $\mathrm{N}$ terminal da histona H3 (H3K9) é um marcador de DNA silenciado (CAO et al., 2002; PETERS et al., 2002; SNOWDEN et al., 2002) e está globalmente distribuído em regiões de heterocromatina, no $\mathrm{X}$ inativado e promotores silenciados. Já H3K4 sugere DNA ativado, predominantemente encontrado em promotores em funcionamento (YAN; BOYD, 2006; KIM; SAMARANAYAKE; PRADHAN, 2009).

O grau de metilação das histonas também está envolvido com a regulação transcricional. A trimetilação de lisina 4 na histona $\mathrm{H} 3$ (H3K4me3) é encontrada em promotores ativos, já H3K9me3 e H3K27me3 está presente em promotores reprimidos (SPADA; VINCENT; THOMPSON, 2005; KOUZARIDES, 2007; FRANZ et al., 2009).

O perfil de modificação de histona é regulado por inúmeras enzimas que, ativamente, adicionam e removem modificações covalentes nas proteínas histonas. Histona acetiltransferase (HATs) e histona metiltransferases (HMTs) adicionam grupos acetil e metil, respectivamente, já as histona deacetilases (HDACs) e as histona demetilases (HDMs) atuam removendo esses grupos (SHI, 2007; HABERLAND et al. 2009). Muitas são as enzimas descritas em cada família e elas interagem entre si e com outros mecanismos para a perfeita manutenção da conformação da cromatina e controle da transcrição. Já foram descritas enzimas específicas que adicionam ou retiram marcas epigenéticas para quase todas as modificações de histona conhecidas 
(KOUZARIDES， 2007; SHARMA; KELLY; JONES, 2010).

Existem fortes evidências de que as modificações de histona são herdadas durante as divisões celulares, porém essa transmissão é muito mais complexa que a vista para a metilação do DNA, principalmente devido à replicação independente das moléculas de histonas. Existem evidências que grupos protéicos importantes para a transmissão de estados de cromatina silenciada (grupo Polycomb) ou ativa (grupo Trithorax) durante o desenvolvimento estejam relacionados, por exemplo, com a manutenção das modificações em H3K27 e H3K4, porém pouco se sabe dos mecanismos de heranças das modificações de histona (SCHUETTENGRUBER et al., 2007; KIM; SAMARANAYAKE; PRADHAN, 2009).

As marcas epigenéticas, tanto metilação do DNA quanto modificações de histona, atuam simultaneamente para regular a transcrição gênica em um processo complexo. É descrito, por exemplo, que HMTs podem direcionar a metilação de DNA a sítios específicos, por meio do recrutamento de DNMTs (TACHIBANA et al., 2008; ZHAO et al., 2009), ou também, já foi observado o recrutamento de HDACs e proteínas ligantes de metilação pela DNA metiltransferase, induzindo ao silenciamento gênico e condensação da cromatina (JONES et al., 1998).

A sincronia dos dois processos é importante para a manutenção da fisiologia celular normal, porém, muito ainda precisa ser esclarecido acerca dessas interações e com outras moléculas, como processos mediados por RNAs, que têm sido evidenciados na associação com cromatina, adicionando ainda mais complexidade ao sistema.

\section{Doenças Humanas}

Os processos epigenéticos são mecanismos altamente complexos, e pequenas falhas no estabelecimento ou manutenção desses podem alterar a fisiologia normal da célula e desencadear o desenvolvimento de doenças.

As alterações epigenéticas podem acontecer devido à alteração de genes envolvidos com a manutenção dessas marcas. Por exemplo, a mutação do gene $D N M T 3 b$ desencadeia uma hipometilação global e está relacionada com a Síndrome ICF (imunodeficiência, instabilidade da região centromérica e anomalias faciais) (MATARAZZO et al., 2008), já mutações no gene ATRX resultam na mudança do perfil de metilação do DNA ribossômico e regiões repetitivas específicas do cromossomo $\mathrm{Y}$ e de regiões subteloméricas, causando a síndrome ATR-X (alfa-talassemia, retardo mental, ligado ao $\mathrm{X}$ ) e mutações no gene $R s k$-2 (enzima fosforilase de histona), associadas com a síndrome Coffin-Lowry (DELAUNOY et al., 2006).

Alterações do perfil epigenético e o desenvolvimento de doenças têm sido bem estudados em síndromes que envolvem genes que estão sobre a influência do imprinting genético. Como já descrito, o imprinting é o fenômeno, regulado por processos epigenéticos, que garantem o silenciamento específico de apenas um alelo de acordo com a origem parental.

Por exemplo, na região $11 \mathrm{p} 15$, há dois centros reguladores de imprinting (ICRs) e sob influência desses há importantes reguladores do crescimento fetal. Por meio de um perfil epigenético normal, genes como $I G F 2$, na ICR1, e $C D K N 1 C$, mapeado na ICR2, possuem uma expressão altamente controlada e compatível com a atividade de apenas um alelo. Falhas nesses processos, como a alteração do perfil de metilação, podem resultar na expressão anormal do IGF2 a partir dos dois alelos ou a perda de expressão no alelo ativo do gene CDKN1C, regulador negativo da proliferação celular, durante o período pré-natal e são encontrados em grande frequência em pacientes com a síndrome de Beckwith-Wiedemann, caracterizada por hipercrescimento (GOMES; SANTOS; RAMOS, 2005).

A síndrome de Silver-Russell, caracterizada 
por hipocrescimento, também tem sido associada com falhas no perfil epigenético da ICR1 da região 11p15. De modo contrário, nas alterações moleculares encontradas na síndrome de BeckwithWiedemann, há hipometilação da região, o que resulta na diminuição da expressão do gene $I G F 2$ no período pré-natal (GICQUEL et al., 2005).

Além das síndromes com alterações epigenéticas clássicas, essas modificações têm sido cada vez mais relacionadas com inúmeras doenças humanas e afetam diferentes tecidos corporais, como em doenças neurodegererativas, autoimune, cardiovasculares, entre outras.

Disfunções cognitivas relacionadas a mudanças no perfil epigenético já foram descritas em síndromes como de Rubinstein-Taybi, Rett, X-frágil e em doenças como de Alzheimer, Huntington, autismo, esquizofrenia, etc, além de já descritas em outras desordens neurológicas como esclerose múltipla, epilepsia, Parkinson, depressão e outras (URDINGUI; SANCHEZ-MUT; ESTELLER, 2009; PLAZAS-MAYORCA; VRANA, 2010).

Como exemplo, foi observado que há uma diminuição no nível de metilação especificamente na camada II do córtex entorrinal, principal região afetada pela patologia de Alzheimer, e essa diminuição relacionada à mudança de expressão em vários genes (MASTROENI et al., 2010). Já na doença de Parkinson, encontrou-se na substância negra do cérebro uma diminuição de metilação do promotor do gene TNF- $\alpha$, uma citocina chave no processo inflamatório envolvido na doença (PIEPER et al.,2008).

Com relação a modificações de histona, verificou-se uma diminuição de acetilação na lisina 40 da $\alpha$-tubilina de cérebros de pacientes com doença de Huntington's, assim como o aumento do nível de H3K9 trimetilada nesses pacientes (RYU et al., 2006; DOMPIERRE et al., 2007).

Alterações epigenéticas também têm sido relacionadas com doenças autoimunes, como a hipometilação encontrada em doenças como lúpus eritematoso, artrite reumatóide, escleroderma e doenças de pele inflamatórias (MILLINGTON, 2008; BROOKS et al., 2010; TRENKMANN et al., 2010).

$\mathrm{Na}$ diabetes tipo I, há uma diminuição de expressão do gene HDAC e aumento da dimetilação em H3K4 em linfócitos, o que pode estar relacionado com a resposta imune alterada dessas células ao destruírem as células $\beta$ produtoras de insulina no pâncreas (COOPER; EL-OSTA, 2010).

Em pacientes com aterosclerose humana, entre outras modificações, foi descrita a hipometilação do DNA em promotores como dismutase superóxido extracelular, receptor de estrógeno $\alpha$, óxido nítrico sintase endotelial e lipoxigenase em amostras retirada da lesão de pacientes (TURUNEN; AAVIK; YLÄHERTTUALA, 2009). A importância da epigenética no desenvolvimento de doenças cardiovasculares se intensifica pelo crescente número de relatos da influência de fatores de risco para essas doenças como alimentação, tabagismo, poluição e estresse, nas alterações de marcas epigenéticas (ORDOVÁS; SMITH, 2010).

\section{Câncer}

A importância dos processos epigenéticas tem sido fortemente enfatizada pelo crescente número de trabalhos relatando falhas tanto nos processos de metilação DNA quanto de modificações de histona em diversos tipos tumorais. Sendo o câncer uma doença genética e epigenética, têm sido descritas alterações epigenéticas em praticamente todos os tipos tumorais, entre eles, câncer de colon, endométrio, hepáticos, do sistema nervoso, de mama, esôfago, bexiga, de pele, leucemias, etc (RODRÍGUEZ-PAREDES; ESTELLER, 2011).

Como processo melhor estudado, modificações no perfil de metilação do DNA têm sido descritos em todos os passos do processo de carcinogênese e o perfil de metilação de células neoplásicas, no geral, é marcado por hipometilação global, o que está 
envolvido com o aumento de instabilidade genética frequentemente verificado no câncer, hipometilação de algumas ilhas $\mathrm{CpGs}$ em regiões promotoras de oncogenes, além de hipermetilação geralmente em regiões promotoras de genes supressores tumorais e genes de reparo celular (KANAI; HIROHASHI, 2007; SHARMA; KELLY; JONES, 2010).

Para se ter uma idéia da importância das alterações de metilação no desenvolvimento neoplásico, foram identificadas 193 e 400 sequências propícias a aberrações no perfil de metilação do DNA na leucemia linfóide crônica e na leucemia linfóide aguda, respectivamente, além de 200 regiões potenciais para desenvolvimento de marcadores moleculares diagnóstico para o câncer de mama (ORDWAY et al., 2007; PLASS et al., 2007; KUANG et al., 2008).

Embora menos conhecido, as modificações de histona também já foram descritas como alteradas em processos tumorais, inclusive relacionadas com parâmetros clínicos da doença, como fatores prognósticos e recorrência (PARK, 2008).

Alterações em proteínas não histonas que reconhecem marcações epigenéticas, essencial para o coreto funcionamento dessas, também já foram descritas, como é o caso da diminuição do nível da proteína HP1, que reconhece a metilação em H3K9, e está associado com a progressão tumoral (DIALYNAS et al., 2008).

Ilhas CpGs, geralmente hipermetiladas em células cancerígenas, têm sido associadas com modificações de histona específicas, como: deacetilação de H3 e H4, perda da trimetilação de H3K4 e ganho de metilação em H3K9 e trimetilação de H3K27 (ESTELLER, 2007).

Pouco se sabe do perfil de modificações de histona global, tanto em células normais, quanto em tumorais, porém a análise do perfil de $\mathrm{H} 4$ revelou evidências de que, em células tumorais, há perda de monoacetilação em K16 e a trimetilação em K20, correspondentemente com as áreas de hipometilação de DNA (FRAGA et al., 2005). O aumento de expressão da enzima HDAC ou mutações na enzima HAT, foram verificados em diversos tipos tumorais compatível com a perda de acetilação verificada (MOORE et al., 2004; JIN et al., 2008; LEHMANN et al., 2009; WANG et al., 2009).

Também é verificado em células cancerígenas, a perda global dos marcadores $\mathrm{H} 3 \mathrm{~K} 4 \mathrm{me} 3$ (ativação gênica), H4K20me3 (repressão) e ganho global dos marcadores repressivos H3K9me e H3K27me3 (HAMAMOTO et al., 2004; FRAGA et al., 2005; VIRE et al., 2006; KONDO et al., 2007).

\section{Terapias Epigenéticas}

Devido ao grande número de doenças causadas por alterações do perfil epigenético, incluindo o câncer, muitas pesquisas têm sido realizadas na busca de drogas capazes de reverter esses defeitos.

Atualmente, já foram descritos muitos agentes capazes de interferir na ação de enzimas que alteram a metilação de DNA ou a modificação de histona. Porém, ainda não se conhecem os mecanismos que guiam essas enzimas para sítios específicos do genoma, por isso essas drogas têm sido pesquisadas no intuito de reverter alterações globais.

Entre os agentes demetilantes do DNA descritos estão 5-azacitidina (5AC, Vidaza), 5-aza-2-deoxicitidina (DAC, decitabina) e 1-(b-Dribofuranosil)-1,2-dihidropirimidina-2-1 (ZEB, Zebularina). Todos esses fármacos são análogos de nucleosídeos, sendo incorporados à molécula de DNA como citosina durante a replicação. Esses análogos ligam-se covalentemente à enzima DNMT, o que inibe a metilação do DNA (GOWHER; JELTSCH, 2004; YOO; JONES, 2006).

Esses compostos têm apresentado boa diminuição da taxa de proliferação celular em inúmeros tipos tumorais, principalmente em doenças hematopoéticas. Devido aos bons resultados em ensaios in vitro e em estudos clínicos, a "US Food and Drug Administration" (FDA) aprovou a utilização da Azacitidina e da Decitabina no 
tratamento da Síndrome Mielodisplásica, entretanto, esses tratamentos têm levado, em alguns indivíduos, à supressão de proliferação de células da linhagem mielóide em geral e problemas de toxicidade (KANTARJIAN et al., 2003). Por outro lado, a Zebularina parece ser um composto mais estável e menos tóxico quando comparado à Azacitidina, e ainda aparentemente muito mais seletiva à célula tumoral (CHENG et al., 2004).

Outra enzima alvo nas buscas de novos tratamentos é a histona deacetilase (HDAC). Existem muitos compostos com atividade inibidora de HDAC descritos e esses, basicamente, são classificados em quatro grupos estruturais. Os inibidores de HDAC (iHDAC) do tipo ácidos hidroxâmicos, entre eles o SAHA, TSA, LBH589, PXD101. O segundo grupo é constituído de ácidos graxos de cadeia curta, como o ácido butírico, OSUHDAC42 e o antipilético ácido valpróico, e também existe o grupo de composto de tetrapeptídeos cíclicos, como o FK228. Esses três grupos agem inibindo HDACs de classes 1 e 2, no quarto grupo estão as benzamidas, MS-275 e MGCD-0103, que inibem além da classe 1 e 2, também a 3 (SZYF, 2009; KRISTENSEN; NIELSEN; HANSEN, 2009).

Cada composto tem um mecanismo de ação próprio, mas a grande maioria dos inibidores interfere no sítio catalítico da enzima, o que resulta no bloqueio do reconhecimento do substrato e no acúmulo de histonas acetiladas (FINNIN et al., 1999). Estudos com inibidores de HDAC têmse mostrado eficazes em diversos tipos tumorais, diminuindo a taxa de proliferação e aumentando apoptose dessas células, e muitos desses compostos estão em ensaios clínicos fase I e II. Mencionase a esse respeito que há aprovação pela US FDA do composto SAHA, no tratamento de linfoma de célula T cutâneo (BELINSKY et al., 2003; MA; EZZELDIN; DIASIO, 2009; MAI; ALTUCCI, 2009).

A grande maioria dos trabalhos descreve a eficiência de inibores de metilação do DNA e
iHDACs, mas também já foram identificados compostos capazes de inibir a acetilação ou metilação de histonas que apresentam potencial anti-neoplásico e no tratamento de outras doenças, como HIV e problemas inflamatórios (GREINER et al., 2005; MANTELINGU et al., 2007; SELVI et al., 2010).

\section{Perspectivas Futuras}

É tanta informação que se tem acerca das regulações epigenéticas e tanto ainda por se conhecer que, cada vez mais, tão qual a importância do genoma da célula, evidencia-se o epigenoma. A regulação epigenética é essencial para o correto funcionamento celular e é reforçada pelo grande número de trabalhos descrevendo alterações no padrão normal em diversas doenças humanas.

Além do entendimento do epigenoma normal celular, estudos demonstrando o perfil epigenético alterado podem ter implicações diretas na prática clínica, e são usados como marcadores moleculares de detecção, progressão e predição de resposta aos tratamentos convencionais. E como já se disse anteriormente, já existem drogas capazes de reverter essas falhas epigenéticas.

Porém, apesar de toda a expectativa na terapia epigenética, existem ainda muitas dúvidas quanto à aplicatividade desses tratamentos, e muitas delas relacionadas com a ativação gênica inespecífica e a desregulação de elementos transponíveis em células normais, além do potencial mutagênico e carcinogênico.

Por outro lado, já se observam que algumas dessas drogas possuem seletividade para células defeituosas e até mesmo para uma fração específica do transcritoma, ou seja, há uma menor ação global do que se esperava (CHIBA et al., 2004; DANNENBERG; EDENBERG, 2006). Além do mais, existem inúmeras drogas em ensaios clínicos tipo I e II e três drogas já aprovadas pelo US FDA.

Os tratamentos epigenéticos são sim uma 
esperança promissora, mas ainda se fazem necessários maiores estudos dos reais riscos e custobenefício, assim como o melhor entendimento dos mecanismos epigenéticos básicos para, no futuro, serem mapeadas vias específicas para interferência e um minucioso controle de efeitos.

\section{Referências}

BELINSKY, S. A.; KLINGE, D. M.; STIDLEY, C. A.; ISSA, J. P.; HERMAN, J. G.; MARCH, T. H.; BAYLIN, S. B. Inhibition of DNA methylation and histone Deacetylation prevents murine lung cancer. Cancer Research, Philadelphia, v. 63, n. 21, p. 7089-7093, 2003.

BOLLATI, V.; BACCARELLI, A. Environmental epigenetics. Chronobiology international, London, v. 27, n. 5, p. 1093-1104, 2010.

BROOKS, W. H.; LE DANTEC, C.; PERS, J. O.; YOUINOU, P.; RENAUDINEAU, Y. Epigenetics and autoimmunity. Journal of autoimmunity, London, v. 34, n. 3, p. 207-219, 2010.

CAO, R.; WANG, L.; WANG, H.; XIA, L.; ERDJUMENTBROMAGE, H.; TEMPST, P.; JONES, R. S.; ZHANG, Y. Role of histone H3 lysine 27 methylation in Polycombgroup silencing. Science, Washington, v. 298, p. 10391043, 2002.

CHENG, J. C.; YOO, C. B.; WEISENBERGER, D. J.; CHUANG, J.; WOZNIAK, C.; LIANG, G.; MARQUEZ, V. E.; GREER, S.; ORNTOFT, T. F.; THYKJAER, T.; JONES, P. A. Preferential response of cancer cells to zebularine. Cancer Cell, Cambridge, v. 6, p. 151-158, 2004.

CHIBA, T.; YOKOSUKA, O.; ARAI, M.; TADA, M.; FUKAI, K.; IMAZEKI, F.; KATO, M.; SEKI, N.; SAISHO, H. Identification of genes up-regulated by histone deacetylase inhibition with cDNA microarray and exploration of epigenetic alterations on hepatoma cells. Journal of hepatology, Oxfordshire, v. 41, n. 3, p. 436445, 2004.

COOPER, M. E.; EL-OSTA, A. Epigenetics: mechanisms and implications for diabetic complications. Circulation Research, Baltimore, v. 107, n. 12, p. 1403-1413, 2010.

DANNENBERG, L. O.; EDENBERG, H. J. Epigenetics of gene expression in human hepatoma cells: expression profiling the response to inhibition of DNA methylation and histone deacetylation. BMC Genomics, London, v. 19, p. 177-181, 2006.

DAVEY, C. S.; PENNINGS, S.; REILLY, C.; MEEHAN,
R. R.; ALLAN, J. A determining influence for $\mathrm{CpG}$ dinucleotides on nucleosome positioning in vitro. Nucleic Acids Research, Londres, v. 32, n. 14, p. 43224331, 2004.

DELAUNOY, J. P.; DUBOS, A.; MARQUES PEREIRA, P.; HANAUER, A. Identification of novel mutations in the RSK2 gene (RPS6KA3) in patients with CoffinLowry syndrome. Clinical genetics, Frederiksberg, v. 70, n. 2, p. 161-166, 2006.

DELAVAL, K.; WAGSCHAL, A.; FEIL, R. Epigenetic deregulation of imprinting in congenital diseases of aberrant growth. BioEssays, Hoboken, v. 28, p. 453-459, 2006.

DIALYNAS, G. K.; VITALINI, M. W.; WALLRATH, L. L. Linking heterochromatin protein 1 (HP1) to cancer progression. Mutation Research, Amsterdam, v. 647, n. 1/2, p. 13-20, 2008.

DOMPIERRE, J. P.; GODIN, J. D.; CHARRIN, B. C.; CORDELIÈRES, F. P.; KING, S. J.; HUMBERT, S.; SAUDOU, F. Histone deacetylase 6 inhibition compensates for the transport deficit in Huntington's disease by increasing tubulin acetylation. Journal of Neuroscience, Baltimore, v. 27, n. 13, p. 3571-3583, 2007.

EGGER, G.; LIANG, G.; APARICIO, A.; JONES, P. A. Epigenetics in human disease and prospects for epigenetic therapy. Nature, London, v. 429, n. 6990, p. 457-463, 2004.

EHRLICH, M. DNA hypomethylation in cancer cells. Epigenomics, London, v. 1, n. 2, p. 239-259, 2009.

ESTELLER, M. Cancer Epigenomics: Dna Methylomes and Histone-Modification Maps. Nature reviews: Genetics, London, v. 8, n. 4, p. 286-298, 2007.

FINNIN, M. S.; DONIGIAN, J. R.; COHEN, A.; RICHON, V. M.; RIFKIND, R. A.; MARKS, P. A.; BRESLOW, R.; PAVLETICH, N. P. Structures of a histone deacetylase homologue bound to the TSA and SAHA inhibitors. Nature, London, v. 401, n. 6749, p. 188-193, 1999.

FRAGA, M. F.; BALLESTAR, E.; VILLAR-GAREA, A.; BOIX-CHORNET, M.; ESPADA, J.; SCHOTTA, G.; BONALDI, T.; HAYDON, C.; ROPERO, S.; PETRIE, K.; IYER, N. G.; PÉREZ-ROSADO, A.; CALVO, E.; LOPEZ, J. A.; CANO, A.; CALASANZ, M. J.; COLOMER, D.; PIRIS, M. A.; AHN, N.; IMHOF, A.; CALDAS, C.; JENUWEIN, T.; ESTELLER, M. Loss of acetylation at Lys16 and trimethylation at Lys20 of histone $\mathrm{H} 4$ is a common hallmark of human cancer. Nature Genetics, New York, v. 37, n. 4, p. 391-400, 2005. 
FRANZ, H.; MOSCH, K.; SOEROES, S.; URLAUB, H.; FISCHLE, W. Multimerization and H3K9me3 binding are required for CDYL1b heterochromatin association. Journal of Biological Chemistry, Baltimore, v. 284, n. 50, p. 35049-35059, 2009.

GEIMAN, T. M.; MUEGGE, K. DNA Methylation in early development. Molecular Reproduction and Development, Hoboken, v. 77, p. 105-113, 2010.

GICQUEL, C.; ROSSIGNOL, S.; CABROL, S.; HOUANG, M.; STEUNOU, V.; BARBU, V.; DANTON, F.; THIBAUD, N.; Le MERRER, M.; BURGLEN, L.; BERTRAND, A. M.; NETCHINE, I.; Le BOUC, Y. Epimutation of the telomeric imprinting center region on chromosome 11p15 in Silver-Russell syndrome. Nat Genet., New York, v. 37, n. 9, p.1003-1007, 2005.

GILBERT, S. F. Ageing and cancer as diseases of epigenesis. Journal of biosciences, Karnataka, v. 34, n. 4, p. 601-604, 2009.

GOLL, M. G.; KIRPEKAR, F.; MAGGERT, K. A.; YODER, J. A.; HSIEH, C. L.; ZHANG, X.; GOLIC, K. G.; JACOBSEN, S. E.; BESTOR, T. H. Methylation of tRNAAsp by the DNA methyltransferase homolog Dnmt2. Science, Washington, v. 311 , n. 5759, p. 395398, 2006.

GOMBERT, W. M.; KRUMM, A. Targeted deletion of multiple CTCF-binding elements in the human C-MYC gene reveals a requirement for CTCF in C-MYC expression. PLoS One, San Francisco, v. 4, n. 7, p. e6109, 2009.

GOMES, M. V.; SANTOS, A. S.; RAMOS, E. S. H19DMR Methylation Analysis In Patients With BeckwithWiedemann Syndrome and Isolated Hemihyperplasia. Genetics and Molecular Biology, Ribeirão Preto, v. 28, p. 210-213, 2005.

GOWHER, H.; JELTSCH, A. Mechanism of inhibition of DNA methyltransfe-rases by cytidine analogs in cancer therapy. Cancer biology \& therapy, Austin, v. 3, p. 1062-1068, 2004.

GREINER, D.; BONALDI, T.; ESKELAND, R.; ROEMER, E.; IMHOF, A. Identification of a specific inhibitor of the histone methyltransferase SU(VAR)3-9. Nature Chemical Biology, New York, v. 1, n. 3, p. 143145, 2005.

HABERLAND, M.; HABERLAND, M.; MONTGOMERY, R. L.; OLSON, E. N. The many roles of histone deacetylases in development and physiology: implications for disease and therapy. Nature Reviews Genetics, London, v. 10, p. 32-42, 2009.

HAMAMOTO, R.; FURUKAWA, Y.; MORITA, M.; IIMURA, Y.; SILVA, F. P.; LI, M.; YAGYU,
R.; NAKAMURA, Y. SMYD3 encodes a histone methyltransferase involved in the proliferation of cancer cells. Nat Cell Biol, v. 6, p. 731-740, 2004.

JIN, K. L.; PAK, J. H.; PARK, J. Y.; CHOI, W. H.; LEE, J. Y.; KIM, J. H.; NAM, J. H. Expression profile of histone deacetylases 1, 2 and 3 in ovarian cancer tissues. Journal of gynecologic oncology, Seul, v. 19, n. 3, p. 18590, 2008.

JINTARIDTH, P.; MUTIRANGURA, A. Distinctive patterns of age-dependenthypomethylation in interspersed repetitive sequences. Physiological Genomics, Bethesda, v. 41, p. 194-200, 2010.

JONES, P. C.; VEENSTRA, G. J.; WADE，P. J.; VERMAAK, D.; KASS, S. U.; LANDSBERGER, N.; STROUBOULIS, J.; WOLFFE, A. P. Methylated DNA and $\mathrm{MeCP} 2$ recruit histone deacetylases to repress transcription. Nature Genetics, New York, v. 19, p. 187191, 1998.

KANAI, Y.; HIROHASHI, S. Alterations of DNA methylation associated with abnormalities of DNA methyltransferases in human cancers during transition from a precancerous to a malignant state. Carcinogenesis, Oxford, v. 28, n. 12, p. 2434-2442, 2007.

KANTARJIAN, H. M.; O'BRIEN, S.; CORTES, J.; GILES, F. J.; FADERL, S.; ISSA, J. P.; GARCIAMANERO, G.; RIOS, M. B.; SHAN, J.; ANDREEFF, M.; KEATING, M.; TALPAZ, M. Results of decitabine (5-aza-2'deoxycytidine) therapy in 130 patients with chronic myelogenous leukemia. Cancer, New York, v. 98 , n. 3, p. 522-528, 2003.

KIM, J. K.; SAMARANAYAKE, M.; PRADHAN, $\mathrm{S}$. Epigenetic mechanisms in mammals. Cellular and molecular life sciences, Basel, v. 66, n. 4, p. 596-612, 2009.

KONDO, Y.; SHEN, L.; SUZUKI, S.; KUROKAWA, T.; MASUKO, K.; TANAKA, Y.; KATO, H.; MIZUNO, Y.; YOKOE, M.; SUGAUCHI, F.; HIRASHIMA, N.; ORITO, E.; OSADA, H.; UEDA, R.; GUO, Y.; CHEN, X.; ISSA, J. P.; SEKIDO, Y. Alterations of DNA methylation and histone modifications contribute to gene silencing in hepatocellular carcinomas. Hepatology Research, Oxford, v. 37, p. 974-983, 2007.

KOUZARIDES, T. Chromatin modifications and their function. Cell, Cambridge, v. 128, p. 693-705, 2007.

KRISTENSEN, L. S.; NIELSEN, H. M.; HANSEN, L. L. Epigenetics and cancer treatment. European Journal of Pharmacology, Amsterdam, v. 625, p. 131-142, 2009. 
KUANG, S. Q.; TONG, W. G.; YANG, H.; LIN, W.; LEE, M. K.; FANG, Z. H.; WEI, Y.; JELINEK, J.; ISSA, J. P.; GARCIA-MANERO, G. Genome-wide identification of aberrantly methylated promoter associated $\mathrm{CpG}$ islands in acute lymphocytic leukemia. Leukemia, London, v. 22, p. 1529-1538, 2008.

LEHMANN, A.; DENKERT, C.; BUDCZIES, J.; BUCKENDAHL, A. C.; DARB-ESFAHANI, S.; NOSKE, A.; MÜLLER, B. M; BAHRA, M.; NEUHAUS, P.; DIETEL, M.; KRISTIANSEN, G.; WEICHERT, W. High class I HDAC activity and expression are associated with RelA/p65 activation in pancreatic cancer in vitro and in vivo. BMC Cancer, London, v. 9, p. 395, 2009.

LI, B.; CAREY, M.; WORKMAN, J. C. The role of chromatin during transcription. Cell, Cambridge, v. 128, p. 707-719, 2007.

MA, X.; EZZELDIN, H. H.; DIASIO, R. B. Histone Deacetylase Inhibitors: Current Status and Overview of Recent Clinical Trials. Drugs, New York, v. 69, n. 14, p. 1911-1934, 2009.

MAI, A.; ALTUCCI, L. Epi-drugs to fight cancer: from chemistry to cancer treatment, the road ahead. The international journal of biochemistry \& cell biology, Amsterdam, v. 41, n. 1, p. 199-213, 2009.

MANTELINGU, K.; REDDY, B. A.; SWAMINATHAN, V.; KISHORE, A. H.; SIDDAPPA, N. B.; KUMAR, G. V.; NAGASHANKAR, G.; NATESH, N.; ROY, S.; SADHALE, P. P.; RANGA, U.; NARAYANA, C.; KUNDU, T. K. Specific inhibition of p300-HAT alters global gene expression and represses HIV replication. Chemistry \& Biology, Cambridge, v. 14, n. 6, p. 645-657, 2007.

MASTROENI, D.; GROVER, A.; DELVAUX, E.; WHITESIDE, C.; COLEMAN, P. D.; ROGERS, J. Epigenetic changes in Alzheimer's disease: Decrements in DNA methylation. Neurobiology of Aging, New York, v. 31, n. 12, p. 2025-2037, 2010.

MATARAZZO, M. R.; DE BONIS, M. L.; VACCA, M.; DELLA RAGIONE, F.; D'ESPOSITO, M. Lessons from two human chromatin diseases, ICF syndrome and Rett syndrome. The international journal of biochemistry \& cell biology, Amsterdam, v. 41, n. 1, p. 117-26, 2008.

MCGARVEY, K. M.; GREENE, E.; FAHRNER, J. A.; JENUWEIN, T.; BAYLIN, S. B. DNA methylation and complete transcriptional silencing of cancer genes persist after depletion of EZH2. Cancer Research, Philadelphia, v. 67, n. 11, p. 5097-5102, 2007.

MILLINGTON, G. W. Epigenetics and dermatological disease. Pharmacogenomics, London, v. 9, n. 12, p. 1835-1850, 2008.
MIRANDA, T. B.; JONES, P. A. DNA Methylation: The Nuts and Bolts of Repression. Journal of cellular physiology, Malden, v. 213, p. 384-390, 2007.

MONK, D.; WAGSCHAL, A.; ARNAUD, P.; MÜLLER, P. S; PARKER-KATIRAEE, L.; BOURC'HIS, D.; SCHERER, S.W.; FEIL, R.; STANIER, P.; MOORE, G. E. Comparative analysis of human chromosome $7 \mathrm{q} 21$ and mouse proximal chromosome 6 reveals a placentalspecific imprinted gene, TFPI2/Tfpi2, which requires EHMT2 and EED for allelic-silencing. Cancer Research, Philadelphia, v. 18, n. 8, p. 1270-1281, 2008.

MOORE, S. D.; HERRICK ,S. R.; INCE, T. A.; KLEINMAN, M. S.; DAL CIN, P.; MORTON, C. C.; QUADE, B. J. Uterine leiomyomata with $\mathrm{t}(10 ; 17)$ disrupt the histone acetyltransferase MORF. Cancer Research, Philadelphia, v. 64, p. 5570-5577, 2004.

MOSS, T. J.; WALLRATH, L. L. Conections between epigenetic gene silencing and human disease. Mutation Research, Amsterdam, v. 1/2, n. 618, p. 163-174, 2007.

NAN, X.; NG, H. H.; JOHNSON, C. A.; LAHERTY, C. D.; TURNER, B. M.; EISENMAN, R. N.; BIRD, A. Transcriptional repression by the methyl-CpG-binding protein MeCP2 involves a histone deacetylase complex. Nature, London, v. 393, n. 6683, p. 386-389, 1998.

OKANO, M.; TAKEBAYASHI, S.; OKUMURA, K.; LI, E. Assignment of cytosine-5 DNA methyltransferases Dnmt3a and Dnmt3b to mouse chromosome bands 12A2$\mathrm{A} 3$ and $2 \mathrm{H} 1$ by in situ hybridization. Cytogenetics and cell genetics, Basel, v. 86, n. 3/4, p. 333-334, 1999.

ORDOVÁS, J. M.; SMITH, C. E. Epigenetics and cardiovascular disease. Nature Reviews Cardiology, London, v. 7, n. 9, p. 510-519, 2010.

ORDWAY, J. M.; BUDIMAN, M. A.; KORSHUNOVA, Y.; MALONEY, R. K.; BEDELL, J. A.; CITEK, R. W.; BACHER, B.; PETERSON, S.; ROHLFING, T.; HALL, J.; BROWN, R.; LAKEY, N.; DOERGE, R. W.; MARTIENSSEN, R. A.; LEON, J.; MCPHERSON, J. D.; JEDDELOH, J. A. Identification of novel high-frequency DNA methylation changes in breast cancer. PLOS ONE, San Francisco, v. 2, p. e1314, 2007.

PARK, Y. S.; JIN, M. Y.; KIM, Y. J.; YOOK, J. H.; KIM, B. S.; JANG, S. J. The global histone modification pattern correlates with cancer recurrence and overall survival in gastric adenocarcinoma. Annals of surgical oncology, Heidelberg, v. 15, n. 7, p. 1968-1976, 2008.

PAULSEN, M.; FERGUNSON-SMITH, A. C. Dna methylation in genomic imprinting, development, and disease. The Journal of pathology, London, v. 195, p. 97 110, 2001. 
PETERS, A. H.; MERMOUD, J. E.; O'CARROLL, D.; PAGANI, M.; SCHWEIZER, D.; BROCKDORFF, N.; JENUWEIN, T. Histone H3 lysine 9 methylation is an epigenetic imprint of facultative heterochromatin. Nature Genetics, New York, v. 30, p. 77-80, 2002.

PIEPER, H. C.; EVERT, B. O.; KAUT, O.; RIEDERER, P. F.; WAHA, A.; WÜLLNER, U. Different methylation of the TNF-alpha promoter in cortex and substantia nigra: Implications for selective neuronal vulnerability. Neurobiology of Disease, San Diego, v. 32, n. 3, p. 521-7, 2008.

PLASS, C. H.; BYRD, J. C.; RAVAL, A.; TANNER, S. M.; DE LA CHAPELLE, A. Molecular profiling of chronic lymphocytic leukemia: genetics meets epigenetics to identify predisposing genes. British journal of haematology, Oxford, v. 139, p. 744-752, 2007.

PLAZAS-MAYORCA, M. D., VRANA, K. E. Proteomic investigation of epigenetics in neuropsychiatric disorders: a missing link between genetics and behavior? Journal of Proteome Research, Washington, v. 10, n. 1, p. 58-65, 2010.

PRADHAN, S.; BACOLLA，A.; WELLS， R. D.; ROBERTS, R. J. Recombinant human DNA (cytosine-5) methyltransferase I: expression, purification, and comparison of de novo and maintenance methylation. The Journal of biological chemistry, Bethesda, v. 274, p. 33002-33010, 1999.

PRENDERGAST, G. C.; LAWE, D.; ZIFF, E. B. Association of Myn, the murine homolog of max, with c-Myc stimulates methylation-sensitive DNA binding and ras cotransformation. Cell, Cambridge, v. 65, p. 395407, 1991.

RODRÍGUEZ-PAREDES, M.; ESTELLER, M. Cancer epigenetics reaches mainstream oncology. Nature Medicine, New York, v. 17, n. 3, p. 330-339, 2011.

RUTHENBURG, A. J.; ALLIS, C. D.; WYSOCKA, J. Methylation of lysine 4 on histone H3: Intricacy of writing and reading a single epigenetic mark. Molecular Cell, Cambridge, v. 25, p. 15-30, 2007.

RYU, H.; LEE, J.; HAGERTY, S. W.; SOH, B. Y.; MCALPIN, S. E.; CORMIER, K. A.; SMITH, K. M.; FERRANTE, R. J. ESET/SETDB1 gene expression and histone H3 (K9) trimethylation in Huntington's disease. Proceedings of the National Academy of Sciences of the United States of America, Washington, v. 103, n. 50, p. 19176-19181, 2006.

SAXONOV, S.; BERG, P.; BRUTLAG, D. L. A genomewide analysis of $\mathrm{CpG}$ dinucleotides in the human genome distinguishes two distinct classes of promoters. Proceedings of the National Academy of Sciences of the
United States of America, Washington, v. 103, n. 5, p. 1412-1417, 2006.

SCHUETTENGRUBER, B.; CHOURROUT, D.; VERVOORT, M.; LEBLANC, B.; CAVALLI, G. Genome Regulation by Polycomb and Trithorax Proteins. Cell, Cambrigde, v. 128, p. 735-745, 2007.

SELVI, B. R.; MOHANKRISHNA, D. V.; OSTWAL, Y. B.; KUNDU, T. K. Small molecule modulators of histone acetylation and methylation: a disease perspective. Biochimica et Biophysica Acta, Amsterdam, v. 1799, n. 10/12, p. 810-28, 2010.

SHARMA, S.; KELLY, T. K.; JONES, P. A. Epigenetics in Cancer. Carcinogenesis, Oxford, v. 31, n. 1, p. 27-36, 2010.

SHI, Y. Histone lysine demethylases: emerging roles in development, physiology and disease. Nature Reviews Genetics, Londres, v. 8, p. 829-833, 2007.

SNOWDEN, A. W.; GREGORY, P. D.; CASE, C. C.; $\mathrm{PABO}, \mathrm{C}$. O. Gene-specific targeting of H3K9methylation is sufficient for initiating repression in vivo. Current biology, London, v. 12, p. 2159-2166, 2002.

SONG, Y.; WU, K.; DHAUBHADEL, S.; AN, L.; TIAN, L. Arabidopsis DNA methyltransferase AtDNMT2 associates with histone deacetylase AtHD2s activity. Biochemical and biophysical research communications, San Diego, v. 396, n. 2, p. 187-192, 2010.

SPADA, F.; VINCENT, M.; THOMPSON, E. M. Plasticity of histone modifications across the invertebrate to vertebrate transition: histone $\mathrm{H} 3$ lysine 4 trimethylation in heterochromatin. Chromosome Research, Dordrecht, v. 13, p. 57-72, 2005.

SUZUKI, M. M.; BIRD, A. DNA methylation landscapes: provocative insights from epigenomics. Nature Reviews Genetics, Londres, v. 9, n. 6, p. 465-476, 2008.

SZYF, M. Epigenetics, DNA Methylation, and Chromatin modifying drugs. Annual Review of Pharmacology and Toxicology, Palo Alto, v. 49, p. 243-63, 2009.

TACHIBANA, M.; MATSUMURA, Y.; FUKUDA, M.; KIMURA, H.; SHINKAI, Y. G9a/GLP complexes independently mediate $\mathrm{H} 3 \mathrm{~K} 9$ and DNA methylation to silence transcription. The EMBO journal, Heidelberg, v. 27, p. 2681-2690, 2008.

TAKAI, D.; JONES, P. A. Comprehensive analysis of CpG islands in human chromosomes 21 and 22. Proceedings of the National Academy of Sciences of the United States of America, Washington, v. 99, n. 6, p. 3740-3745, 2002.

TAKEBAYASHI, S.; TAMURA, T.; MATSUOKA, C.; OKANO, M. Major and essential role for the DNA methylation mark in mouse embryogenesis and stable 
association of DNMT1 with newly replicated regions. Molecular and Cellular Biology, Washington, v. 27, p. 8243-8258, 2007.

TRENKMANN, M.; BROCK, M.; OSPELT, C.; GAY, S. Epigenetics in Rheumatoid Arthritis. Clinical Reviews in Allergy and Immunology, Palo Alto, v. 39, p. 10-19, 2010.

TURUNEN, M. P.; AAVIK, E.; YLÄ-HERTTUALA, S. Epigenetics and atherosclerosis. Biochimica et Biophysica Acta, Amsterdam, v. 1790, n. 9, p. 886-891, 2009.

URDINGUIO, R. G.; SANCHEZ-MUT, J. V.; ESTELLER, M. Epigenetic mechanisms in neurological diseases: genes, syndromes, and therapies. Lancet Neurology, London, v. 8, n. 11, p. 1056-1072, 2009.

VERONA, R. I.; MANN, M. R.; BARTOLOMEI, M. S. Genomic imprinting: intricacies of epigenetic regulation in clusters. Annual Review of Cell and Developmental Biology, Palo Alto, v. 19, p. 237-259, 2003.

VIRE, E.; BRENNER, C.; DEPLUS, R.; BLANCHON, L.; FRAGA, M.; DIDELOT, C.; MOREY, L.; VAN EYNDE, A.; BERNARD, D.; VANDERWINDEN, J. M.; BOLLEN, M.; ESTELLER, M.; DI CROCE, L.; DE LAUNOIT, Y; FUKS, F. The Polycomb group protein EZH2 directly controls DNA methylation. Nature, London, v. 439, p. 871-874, 2006.

WANG, L.; ZOU, X.; BERGER, A. D.; TWISS, C.; PENG, Y.; LI, Y.; CHIU, J.; GUO, H.; SATAGOPAN, J.; WILTON, A.; GERALD, W.; BASCH, R.; WANG, Z.; OSMAN, I.; LEE, P. Increased expression of histone deacetylaces (HDACs) and inhibition of prostate cancer growth and invasion by HDAC inhibitor SAHA. American journal of translational research, Madison, $\mathrm{v}$. 1, n. 1, p. 62-71, 2009.

WANG, Y.; LEUNG, F. C. An evaluation of new criteria for $\mathrm{CpG}$ islands in the human genome as gene markers. Bioinformatics, Oxford, v. 20, p. 1170-1177, 2004.

WOLFFE, A. P.; GUSCHIN, D. Chromatin structural features and targets that regulate transcription. Journal of Structural Biology, Amsterdam, v. 129, p. 102-122, 2000.

YAN, C.; BOYD, D. D. Histone H3 acetylation and H3K4 methylation define distinct chromatin regions permissive for transgene expression. Molecular and Cellular Biology, Washington, v. 26, p. 6357-6371, 2006.

YOO, C. B.; JONES, P. A. Epigenetic therapy of cancer: past, present, future. Nature, London, v. 5, n. 1, p. 37-50, 2006.

ZHAO, Q.; RANK, G.; TAN, Y. T.; LI, H.; MORITZ, R. L.; SIMPSON, R. J.; CERRUTI, L.; CURTIS, D. J.;
PATEL, D. J.; ALLIS, C. D.; CUNNINGHAM, J. M.; JANE, S. M. PRMT5-mediated methylation of histone H4R3 recruits DNMT3A, coupling histone and DNA methylation in gene silencing. Nature structural \& molecular biology, New York, v. 16, p. 304-311, 2009.

Recebido em 03 de novembro de 2010

Aceito em 30 de setembro de 2011 
